\title{
Estimating social network size using network scale-up method (NSUM) in Iranshahr, Sistan and Baluchestan Province, Iran
}

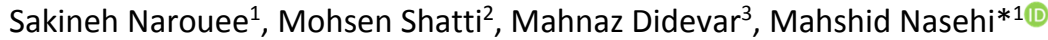

Received: 21 Jan 2018

Published: 18 Apr 2020

\begin{abstract}
Background: The network scale-up method is an indirect method of estimating the size of hidden and hard-to-reach populations. An important prerequisite in this method is to estimate the size of an active social network, as considered in the present study.

Methods: In 2015, the social network size was calculated using the known subpopulation approach and maximum likelihood estimation in the central, Bampur, and Bazman districts of Iranshahr province. Individuals older than 18 years took part in a street-based survey. The relationship between the demographic variables and social network size estimation was analyzed $(\mathrm{p}<0.05)$. Linear regression was used to investigate the relationship of each known subpopulation with underlying variables. Data were analyzed in Excel 2010 and SPSS 19.

Results: From among 1000 participants, 50.2\% lived in rural areas. The social network size of the residents of Iranshahr was estimated to be 308.35 with 12 remaining subgroups. The Pearson's correlation coefficient between the real and estimated values in known subpopulations was equal to $0.92(\mathrm{p}=0.001)$. Men aged 25-39 years, those with high education levels, employees, and those residing in villages had a wider social network. The estimated social network size had a significant relationship with gender, education level, and place of residence $(\mathrm{p}<0.001)$.

Conclusion: The estimated social network size in Iranshahr was smaller than the value reported by a nationwide study (the ratio-based
\end{abstract} method).

Keywords: Network scale-up, Population size estimation, Social network size, Hidden population

Conflicts of Interest: None declared

Funding: The present study was supported by Iran University of Medical Sciences, Tehran, Iran, with the collaboration of Iranshahr University of Medical Sciences and Health Services, Sistan and Baluchestan Province.

*This work has been published under CC BY-NC-SA 1.0 license.

Copyright $\odot$ Iran University of Medical Sciences

Cite this article as: Narouee S, Shatti M, Didevar M, Nasehi M. Estimating social network size using network scale-up method (NSUM) in Iranshahr, Sistan and Baluchestan Province, Iran. Med J Islam Repub Iran. 2020 (18 Apr);34:35. https://doi.org/10.47176/mjiri.34.35

\section{Introduction}

For appropriate planning, evaluation, budget allocation, and HIV prevention programs, the size of hidden or hardto-reach populations must be estimated. Such populations include injection drug users, female sex workers and their clients, and men who have sex with men (MSM). An essential part of health system management is the HIV care system $(1,2)$. The multiplier and capture-recapture are common sampling methods which cannot provide an accurate estimation of hidden populations $(3,4)$. These methods are not fully functional due to the complexity of determining those with high-risk behaviors and can significantly reduce

Corresponding author: Dr Mahshid Nasehi, nasehi.m@iums.ac.ir

1. Department of Epidemiology, School of Public Health, Iran University of Medical Sciences, Tehran, Iran

2. Mental Health Research Center, School of Behavioral Sciences and Mental Health, Tehran Institute of Psychiatry, Iran University of Medical Sciences, Tehran, Iran

3. Iranshahr University of Medical Sciences, Sistan and Balouchestan, Iran the reliability of responses $(1,4,5)$.

The network scale-up (NSU) method with an indirect approach is one of the best data collection methods of hidden populations. In this method, individuals are asked how many people they know in their network of acquaintances who have specific high-risk behaviors. The basic principle in using the NSU method is that the social network size describes general population features and is a prerequisite for calculating the hidden population size in the community (1, $6)$. Therefore, the social network size of individuals in target subpopulations of any study is directly associated with

$\uparrow$ What is "already known" in this topic:

Network scale-up (NSU), with an indirect approach, is one of the best data collection methods of hidden populations.

$\rightarrow$ What this article adds:

In this study, the importance of the size of a regional social network was delineated. 
its real size in the general population (5).

The network scale-up method is used in various countries such as the USA, Ukraine, China, Japan, and Thailand. Similar studies have also been performed for social network size estimation in Brazil, Rwanda, and Moldova. Calculated estimates vary from 55 to 399 and are between 308 and 380 in Iran. Therefore, the difference in social network size in different studies shows the importance of regional studies $(1,5)$.

Sistan and Baluchestan Province is located in Southeast of Iran, bordering with Afghanistan and Pakistan, which are among the largest drug producers in the world. The city of Iranshahr in this province with specific regional, ethnic, cultural, and social features is close to the city of Sarbaz. This city is located in the center of Sistan and Baluchestan province on the path of foreigners and drug transit. Studies demonstrate that cultural and social differences affect social network size (2). The present study was conducted to estimate the social network size of residents of Iranshahr with the population of 265316 in 2015 to provide a population estimate of groups such as drug users in the city. To this end, the effect of different factors was examined on social network size using estimation correction methods.

\section{Methods}

In total, 1000 people, equally composed of men and women, participated in this cross sectional study. Women made up $50.2 \%$ of the population of Iranshahr. About $15.7 \%$ of the general population of the city belonged to 18 24 age group and $21.33 \%$ to $25-39$ age group. Moreover, 710,250 , and 40 of the participants were surveyed in the central, Bampur, and Bazman districts, respectively. The survey was conducted with nearly equal sampling ratios of 49.8 in urban areas and 50.2 in populated rural areas. The study sample was selected using the street-based simple sampling method from among those who were alone in crowded areas such as streets, parks, hospitals, clinics, and taxi stations. The participants aged over 18 years and had lived in Iranshahr for at least 5 years. The questionnaires were filled out by 4 local trained inquirers in Iranshahr in a face-to-face manner by respecting sex-matching between the inquirer and the participant and after explaining the research objectives and obtaining informed consent from the participants. The inquirers asked the participants whether they knew someone in a certain subgroup. The term "knowing" reflected the followings: (1) Person A knows person B and vice versa by name and face; (2) they are in touch face to face, by phone, or email at least once in the last 2 years; and ( 30 person B also lives in Iranshahr; this was consistent with the definition used in different studies $(1,7)$. Further, in case of the response "Yes", the next question was how many people they knew with the specific feature from relevant subgroups (Appendix Table 1). In this study, 30 known population subgroups were used with available information in various organizations, whose total frequency was $20 \%$ of the total population in Iranshahr (Appendix Table 1) $(4,7)$. Several factors were considered in selecting final subpopulations. Subpopulations with impossible accurate access to information were excluded. Therefore, 2 subgroups (people who went abroad or joined the military during the last year) were excluded at the beginning of the study. Then, subpopulations with a relative frequency of $0.1 \%$ to $4 \%$ of the total population of Iranshahr were selected. In this stage, 14 inappropriate subpopulations were removed. Various errors that could have affected the final result were considered in calculating the social network size. Therefore, subpopulations that increased the possibility of probable error in the study with no proper correction method were also excluded from the list of subpopulations. Names with more popularity among people during the last 3 decades and an approximately even distribution were selected. Finally, 16 subpopulations were selected as the sample for further study. These subpopulations included firstgraders, university entrance exam participants, state university students, elementary school employees, married people, those who had a normal delivery or cesarean section, those with thalassemia major, and those with intellectual disability, and those named Asieh, Abdullah, Samira, Yasser, Yasna, Matin, or Omar.

In calculating the social network size with the known subpopulation approach and maximum likelihood estimation (MLE), Formula 1 was used where $\hat{c}_{i}$ is the social network size of the participant $\mathrm{i}, m_{i j}$ is the number of people that the person $\mathrm{i}$ knows from the known group $\mathrm{j}, e_{j}$ is the real population size of the known group $\mathrm{j}$, and $\mathrm{t}$ is the total number of base population in the desired area.

$$
\text { 1. } \hat{\mathrm{c}}_{i}=\left(\sum_{j} m_{i j} / \sum_{j} e_{j}\right) . \mathrm{t}
$$

The estimation standard error was calculated to compute the $95 \%$ confidence interval of the social network size using Formula 2.

\section{2. $\mathrm{SE} \hat{c}_{i}=\sqrt{\hat{\mathrm{c}}_{i} \mathrm{t} /} \sum_{j} e_{j}$}

In the NSU method, there are 3 important assumptions which can respectively cause barrier effect, transmission error, and estimation effect if not available: (a) participants have equal probability of knowing each member of the studied subpopulation in the study; (b) participants have full knowledge of their social network; and (c) it is not highly difficult for them to remember the number of people in their social network and they can remember the number of social networks clearly and quickly. In different studies, various correction methods are employed to reduce the effect of the noted errors so that the accurate social network size can be estimated. In this study, acquaintances who were in the respondents' social network but were not residents of Iranshahr were eliminated from all estimations. Moreover, all the responses recorded for known populations were top-coded to $30(8,9)$. Another method used in this study to increase the accuracy of estimating the social network size was the back estimation of each known population to determine the best groups. The researchers used the back estimation correction method to compare the real size and estimated size of each subpopulation. Thus, the size of each known subpopulation was considered unknown $\left(\hat{\mathrm{e}}_{0}\right)$; then, the size of each subpopulation was estimated using Formula 3. At this point, the estimated/real ratio $(\mathrm{E} / \mathrm{R}$ ratio) for each known subpopulation was calculated by dividing the estimated population size by the real sizes throughout the province. Any subpopulation whose ratio did not fall in the range of 0.5-2 was located in the removal queue of known subgroups and the social network size was 
recalculated without that subgroup. Therefore, the next step was the removal of the first known subgroup whose numerical value had the greatest distance from the 0.5-2 range. All the analysis and calculation steps were repeated without that specific known group. The calculation of ratio for each population, removal of the farthest group from the desired range, and repetition of calculations were reiterated until none of the calculated ratios was outside the desired range. Next, the remaining subpopulations were used to calculate the final social network size.

$$
\text { 3. } \hat{\mathrm{e}}_{0}=\left(\sum_{i} m_{i} / \sum_{i} \hat{\mathrm{c}}_{i}\right) \cdot \mathrm{t}
$$

Finally, the relationship was analyzed between the demographic variables (age, gender, level of education, occupation, and place of residence) and social network size of the residents of Iranshahr. Linear regression was used to investigate the relationship of each known subpopulation with underlying variables. Data were analyzed in Excel 2010 and SPSS 19.

\section{Results}

In this study, 1000 participants aged over 18 years were surveyed and the highest frequency was related to 25-39 age group (49.1\%). Over half of the participants lived in rural areas and were married, $44.3 \%$ had high school diploma and bachelor's degree, and $38.6 \%$ were service providers. Table 1 shows the demographic data of the sample selected in the study.

Using the MLE and 16 known subgroups, the average social network size in Iranshahr was calculated as $355.24(\mathrm{C}=$ $355.24,95 \%$ CI 339.64, 370.85). This size was used for the back estimation of the known populations $\left(\mathrm{e}_{\mathrm{ij}}\right)$. The Pearson correlation coefficient between the real sizes of the known populations and estimated values was $0.85(\mathrm{p}<0.001)$. Except for the 4 known subgroups of "Omar", "Matin", intellectual disability, and thalassemia major, in which the ratio was out of the 0.5-2 range, the other known subpopulations had E/R ratios in the desired range. Therefore, the social network size of the residents of Iranshahr was calculated after the removal of each of the above-mentioned subpopulations.

Table 2 displays the estimated social network size after the 4 noted subgroups were removed. E/R ratio for the population whose sizes were calculated based on estimated network sizes continued to be out of the desired range, and E$\mathrm{R}$ was correlated after the removal of each above-mentioned subgroup. After the removal of the subpopulations "Omar", "Matin", intellectual disability, and thalassemia major, the social network size equaled 355.24, 330.63, 319.52 , and 314.14 , respectively. The correlation coefficient between the real sizes of the known populations and estimated sizes of remaining groups was gradually improved (The R-value based on all the groups was $0.85,0.92$, $0.92,0.91$, and 0.92 , respectively, after the removal of

Table 1. Demographic data of the studied population

\begin{tabular}{|c|c|c|c|c|c|c|c|c|}
\hline \multirow{3}{*}{$\begin{array}{l}\text { Variables } \\
\text { Place of residence }\end{array}$} & & & & & \multicolumn{2}{|l|}{$\mathrm{N}$} & \multicolumn{2}{|l|}{$\%$} \\
\hline & \multicolumn{4}{|l|}{ Urban } & \multicolumn{2}{|l|}{458} & \multicolumn{2}{|c|}{49.8} \\
\hline & \multicolumn{4}{|l|}{ Rural } & \multicolumn{2}{|l|}{502} & \multicolumn{2}{|c|}{50.2} \\
\hline \multirow[t]{2}{*}{ Gender } & \multicolumn{4}{|l|}{ Male } & \multicolumn{2}{|l|}{500} & \multicolumn{2}{|c|}{50} \\
\hline & \multicolumn{4}{|l|}{ Female } & \multicolumn{2}{|l|}{500} & \multicolumn{2}{|l|}{50} \\
\hline \multirow[t]{3}{*}{ Age (year) } & \multicolumn{4}{|l|}{$18-24$} & \multicolumn{2}{|l|}{355} & \multicolumn{2}{|c|}{35.5} \\
\hline & \multicolumn{4}{|l|}{$25-39$} & \multicolumn{2}{|l|}{491} & \multicolumn{2}{|c|}{49.1} \\
\hline & \multicolumn{4}{|l|}{$>40$} & \multicolumn{2}{|l|}{154} & \multicolumn{2}{|c|}{15.4} \\
\hline \multirow[t]{3}{*}{ Marital status } & \multicolumn{4}{|l|}{ Single } & \multicolumn{2}{|l|}{284} & \multicolumn{2}{|c|}{28.4} \\
\hline & \multicolumn{4}{|l|}{ Married } & 699 & & 69.9 & \\
\hline & Divorced $\mathrm{Wic}$ & ed & & & 17 & & 1.7 & \\
\hline Level of education & Illiterate Elen & tary sch & & & 217 & & 21.7 & \\
\hline & Secondary sch & & & & 332 & & 33.2 & \\
\hline & High school d & ma thro & bachel & degree & 44 & & 44.3 & \\
\hline & Above bachel & degree & & & 8 & & 0.8 & \\
\hline Occupation & Employee & & & & 85 & & 8.5 & \\
\hline & Service provid & & & & 386 & & 38.6 & \\
\hline & University stu & & & & 96 & & 90.6 & \\
\hline & Homemaker & & & & 334 & & 33.4 & \\
\hline & Unemployed/1 & tary ser & memb & & 95 & & 9.5 & \\
\hline & Retired & & & & 4 & & 0.4 & \\
\hline Estimation steps & Average so- & & & $\mathrm{E} / \mathrm{R}$ ra & & & E-R corr & \\
\hline & $\begin{array}{l}\text { cial network } \\
\text { size }\end{array}$ & Omar & Matin & $\begin{array}{c}\text { Intellectual } \\
\text { disability }\end{array}$ & $\begin{array}{l}\text { Thalassemia ma- } \\
\text { jor }\end{array}$ & Total & Coefficient & $\mathrm{p}$ \\
\hline With 16 known subgroups & 355.24 & 6.18 & 1.58 & 0.91 & 1.84 & 1.60 & 0.85 & $<0.001$ \\
\hline $\begin{array}{l}\text { All the known populations, ex- } \\
\text { cept for Omar }\end{array}$ & 330.63 & - & 3.06 & 2.08 & 1.98 & 1.29 & 0.92 & $<0.001$ \\
\hline $\begin{array}{l}\text { All the known populations, ex- } \\
\text { cept for Omar and Matin }\end{array}$ & 319.52 & - & - & 2.16 & 2.04 & 1.25 & 0.92 & $<0.001$ \\
\hline $\begin{array}{l}\text { All the known populations, ex- } \\
\text { cept for Omar, Matin, and in- } \\
\text { tellectual disability }\end{array}$ & 314.14 & - & - & - & 2.08 & 1.21 & 0.91 & $<0.001$ \\
\hline $\begin{array}{l}\text { All the known populations, ex- } \\
\text { cept for Omar, Matin, intellec- } \\
\text { tual disability, and thalassemia } \\
\text { major }\end{array}$ & 308.35 & - & - & - & - & 1.17 & 0.92 & $<0.001$ \\
\hline
\end{tabular}


"Omar", "Matin", "intellectual disability", and "thalassemia major.").

Table 3 presents the back estimation results of the known subpopulations in the desired range that were incorporated in the final estimation of the social network size. The final social network size was 308.35 , as calculated using 12 remaining known subpopulations $(\mathrm{C}=308.35$, 95\% CI 294.33, 322.37).

In the univariate analysis, the variables of gender $(p<0.001)$, marital status $(p=0.01)$, education level $(p=0.01)$, occupation $(p=0.003)$, and place of residence $(\mathrm{p}<0.001)$ had a significant relationship with the social network size. Men had a larger social network than women (338.08 vs 278.6). Moreover, single participants had a larger social network than the married (331.5 vs 301.6). Additionally, those with a higher education level had a larger social network than those with a lower education level, and those who were illiterate or had an elementary education level had a limited social network (362.4 vs 221.3). Furthermore, employees had a wider social network and homemakers had a limited social network (467.7 vs 260.9).

Based on multivariate analysis, the variables of gender, education level, and place of residence were recognized as factors affecting the social network size $(\mathrm{p}<0.001)$ (Table 4).

\section{Discussion}

Based on the findings of this study, the active social network size of the residents of Iranshahr was 308.35 using MLE and the known subpopulations approach. In this study, 12 known subpopulations in the range of $0.5-2$ were employed for the estimation of C-value. Men and women had different social network sizes and the variables of gender, education level, and place of residence were identified as factors affecting the social network size.

In this study, the active social network size was reduced from 355.24 to 308.35 with the removal of the known subpopulations not in the desired range. Similar to other studies, this study showed that the use of all known subgroups was not desirable for social network estimation and that the stepwise removal of inappropriate subgroups to increase the internal validity of the study was an approach which, if not followed, may lead to errors in estimations $(1,10,11)$.

In the present study, the back estimation of the known groups had a high correlation with their real sizes $(r=0.85)$

\begin{tabular}{|c|c|c|c|c|c|c|}
\hline \multicolumn{2}{|l|}{ Reference group } & \multicolumn{2}{|c|}{ Organization providing the data } & \multirow{2}{*}{$\begin{array}{c}\text { Real size (proportion } \\
\% \text { ) }\end{array}$} & & \multirow[b]{2}{*}{ E/R Ratio } \\
\hline & & & & & $\begin{array}{l}\text { Estima- } \\
\text { tion }\end{array}$ & \\
\hline \multicolumn{2}{|c|}{ Started elementary school last year } & \multicolumn{2}{|c|}{ Provincial Education Organization } & $7584(2.85)$ & 5687 & 0.74 \\
\hline \multicolumn{2}{|c|}{$\begin{array}{l}\text { Took part in university entrance exam last } \\
\text { year }\end{array}$} & \multicolumn{2}{|c|}{ Organization of Educational Testing } & $3726(1.40)$ & 2081 & 0.55 \\
\hline \multirow{2}{*}{\multicolumn{2}{|c|}{ Started studying at a state university last year }} & \multicolumn{2}{|c|}{ Organization of Educational Testing } & $1105(0.41)$ & 1353 & 1.22 \\
\hline & Officially married last year & \multicolumn{2}{|c|}{ Provincial Registration Organization } & $2018(0.79)$ & 2866 & 1.42 \\
\hline \multicolumn{2}{|c|}{ Had a normal delivery last year } & \multicolumn{2}{|c|}{$\begin{array}{l}\text { Deputy Minister of Health of } \\
\text { Iranshahr }\end{array}$} & $2583(1.00)$ & 1982 & 0.76 \\
\hline \multicolumn{2}{|c|}{ Had a cesarean section last year } & \multicolumn{2}{|c|}{$\begin{array}{l}\text { Deputy Minister of Health of } \\
\text { Iranshahr }\end{array}$} & $471(0.17)$ & 690 & 1.46 \\
\hline \multicolumn{2}{|c|}{ Had an office job in an elementary school } & \multicolumn{2}{|c|}{ Provincial Education Organization } & $2107(0.82)$ & 2589 & 1.22 \\
\hline \multicolumn{2}{|c|}{ Asieh } & \multicolumn{2}{|c|}{ National Registration Organization } & $2027(0.76)$ & 2276 & 1.12 \\
\hline \multicolumn{2}{|l|}{ Abdullah } & \multicolumn{2}{|c|}{ National Registration Organization } & $1619(0.61)$ & 2166 & 1.33 \\
\hline \multicolumn{2}{|l|}{ Samira } & \multicolumn{2}{|c|}{ National Registration Organization } & $1033(0.38)$ & 1787 & 1.73 \\
\hline Yasser & & \multicolumn{2}{|c|}{ National Registration Organization } & $1013(0.38)$ & 1795 & 1.77 \\
\hline Yasna & & \multicolumn{2}{|c|}{ National Registration Organization } & $790(0.29)$ & 806 & 1.02 \\
\hline \multicolumn{7}{|c|}{ able 4. Comparing the average social network size in the underlying subpopulations } \\
\hline Variable & Variable states & & $\mathrm{C} \mathrm{m}$ & (SE) & $\begin{array}{c}\text { Crude } \\
\text { p-value }\end{array}$ & $\begin{array}{c}\text { Adjusted } \\
\text { p-value }\end{array}$ \\
\hline Gender & Male & & 338. & 10.5) & $<0.001$ & $<0.001$ \\
\hline & Female & & 278 & 9.4) & & \\
\hline Age (year) & $18-24$ & & 300 & $1.1)$ & 0.402 & \\
\hline & $25-39$ & & 319 & 10.5) & & - \\
\hline & $>40$ & & 291 & 18.9) & & \\
\hline Education & Illiterate Elementary & & 221 & $1 / 7)$ & $<0.001$ & $<0.001$ \\
\hline & Secondary school & & 301 & $1.0)$ & & \\
\hline & High school diploma thro & h bachelor's degree & 354 & $1.8)$ & & \\
\hline & Above bachelor's degree & & 362. & 29.5) & & \\
\hline Marital status & Single & & 331 & 14.8) & 0.014 & 0.823 \\
\hline & Married & & 301 & $8.1)$ & & \\
\hline & Divorced Widowed & & 198 & 37.3) & & \\
\hline Occupation & Employee & & 467 & $1.7)$ & 0.003 & 0.642 \\
\hline & Service provider & & 293 & 9.7) & & \\
\hline & University student & & 335 & $3.3)$ & & \\
\hline & Homemaker & & 260 & 9.9) & & \\
\hline & Unemployed/ Military ser & ce member & 363 & 23.6) & & \\
\hline & Retired & & 353 & 15.7) & & \\
\hline Place of residence & City & & 281. & 29.9) & $<0.001$ & $<0.001$ \\
\hline & Village & & 334.7 & $0.71)$ & & \\
\hline
\end{tabular}


and the correlation coefficient increased to 0.92 after the removal of inappropriate known subpopulations. In another study in Iran, the correlation coefficient between back estimation and real size was similar and equal to 0.95 using regression and ratio-based methods. However, the ratiobased method had a better performance. In a study in Tehran, the correlation coefficient between the back estimation of the size of known populations and their real values was doubled after the removal of 3 inappropriate subgroups (0.82 vs 0.32$)(11,1)$.

In a study performed in Ukraine, the correlation coefficient increased from 0.91 to 0.94 after removing 9 groups of known subpopulations $(1,11,12)$. Studies conducted in Tbilisi, Shanghai, China, and the United States also demonstrated that the correlation coefficient between the back estimation of known subgroups and the real size increased with the removal of inappropriate subgroups $(0.86,0.88$, and 0.94 , respectively) $(1,13,14)$. It appears that the use of large known subpopulations is associated with estimation error because of the recall bias affecting the correlation coefficient.

In the present study, the average $\mathrm{E} / \mathrm{R}$ ratio was 1.60 , which approached 1 and reached 1.17 with the removal of each inappropriate subpopulation, indicating a $17 \%$ overestimation of the known subpopulations in this study.

According to Shati et al, the average value of the E/R ratio was 1.09 , indicating a $9 \%$ overestimation of the target population (1). The average value in the study in Ukraine was 1.65 , demonstrating a $65 \%$ overestimation of the known population (12). Overestimation is considered as a limitation of the NSU method in estimating small known subpopulations (1). In the present study, this problem was present in the preliminary estimation of the "Omar" subpopulation, which accounts for $0.3 \%$ of the city population. This difference might have been due to the presence of people in the social network of participants whose names were not officially Omar but were known by that name. With the stepwise removal of the subgroups of Omar, Matin, intellectual disability, and thalassemia major, the $\mathrm{E} / \mathrm{R}$ ratio was further reduced and approached $1($ The $\mathrm{E} / \mathrm{R}$ ratio $=1.17)$.

In the present study, first-graders, those preparing for the university entrance exam, and those with natural delivery constituted the largest subgroups. The estimation of the university entrance exam group in the first step was associated with underestimation, which entered the acceptable range after the removal of the "Omar" subgroup (the E/R ratio= 0.52). However, the first-graders and natural delivery groups had more accurate estimations, which could have been due to the satisfactory transmission of these populations and more accurate knowledge of participants of these features. In a study in Tehran, the population estimation of the first-graders subgroup was associated with underestimation and the natural delivery subgroup with estimation error, which attributed to the higher awareness of women. In another study in the United States, Killworth et al showed that it was difficult for participants to recall the number of acquaintances in large subpopulations (1). A study in Rwanda also reported that the use of less information associated with incredible events led to more accurate estimates (15-17). Therefore, another computational error that should be considered in the NSU method is the underestimation of large subgroups (4).

In a study in Iran, there were 2 estimates with 23 subgroups. The social network size in this study was estimated at 308 and 380 using regression and ratio-based approaches, respectively. In the regression-based method, there was a linear association between the prevalence of reference groups in the society (eg, E/T) and the average number of people who respondents knew in each reference group (eg, mean of $\mathrm{m}$ ). Moreover, the ratio-based method had a similar approach to that used in the present study. According to the results of this research, the ratio-based approach, which was also used in the present study, was better than the regression-based approach because of its better internal validity, predictive validity, and removal of known subpopulations not within the desired range $(1,11)$. In a study in Iran, the population size ratio of 10 groups from 23 known subpopulations to the total out-of-range population was $0.1 \%-4 \%$, and thus was not used in social network size estimation. In the present study, with the removal of 14 subgroups that fell out of the $0.1 \%-4 \%$ range, the social network size with 12 known subgroups and best ratio equaled 308.35 , which was smaller than the value obtained through the ratio-based approach in the national study. This difference may be due to the fact that the social network of people was nationwide in a national study, in this study, this number was estimated in a province (11).

In a study conducted by Jafari et al using 12 subpopulations in Tabriz, the social network size was estimated at 113.85. The large difference between this value and the social network size obtained in the present study may be due to the fact that the social network size was estimated only in Tabriz in the noted study, while the social network size was calculated by sampling the entire city of Iranshahr in the present research. The vastness of the area, where the study was conducted, can affect the average social network size of individuals (18). Another reason for difference in the results was the difference in the definitions of "knowing". In the present study, one of the conditions of "knowing" was having contact through phone or email at least once in the last 2 years. However, in the study in Tabriz, the definition was having at least one contact in the past year. The difference in the definition can cause a difference in the number of people who the participants know, leading to a variation in the social network size. Another important difference was the dissimilarity in sampling methods between the 2 studies. While Jafari et al used purposive sampling, street-based random sampling, suitable for sensitive questions, was used in the present study (18).

Similar to the study by Shati et al, the present study revealed that the social network size of men was higher than that of women (338.08 vs 278.6). Although women's role in social activities has increased in recent decades, it appears that men still have wider networks (10).

In a national study, the social network size of women was 274, which was not significantly different from the value estimated in the present study. However, according to Shati et al, the average social network size of women was 230 and lower than the present study. The difference can be re- 
lated to the greater unity of women due to ethnical and cultural conditions and differences from Tehran in terms of urbanization features. Women usually communicate with fewer people, but their links are stronger. In a study by Zamanian et al (2016) in Kerman, the social network size of women was estimated at 234. This estimation was lower than the estimation made in Iranshahr, which might have been due to the multistage sampling method used in the study in Kerman that classified the city into 3 socioeconomic classes. Then, five regions were randomly selected from each category as clusters. Finally, in crowded streets of each region, pedestrians were recruited in accordance with the age distribution of women using the convenience sampling approach. However, in the present study, interviews were conducted in main streets and crowded places. In addition, in the study in Kerman, the only known subgroups were name subgroups using 25 names (13 female and 12 male) and, contrary to the present study, the target group was Kermani women over 18 years $(1,19,20)$.

In the national study in Iran, the C-value was calculated to be 344.72 for men, which was not significantly different from the value estimated in the present study. This value was calculated equal to 259 for men in the study in Tehran, which was lower than the value reported in the present study. This difference can be because men in Iranshahr were more connected to one another due to cultural, ethnical, and tribal characteristics. In the study by Shokoohi et al, although different numbers were obtained for $\mathrm{C}$, the final social network size using MLE was close to the results of the present study. The noted study was conducted on 500 men aged 18-45 years and data were collected through interviews. The definition of "knowing" in this study was not limited to Kerman and participants also reported knowing people from other cities. However, in this study, respondents were asked to report the number of people in Iranshahr $(11,18,5)$.

In a study estimating the MSM population size, Ezoe et al assessed the social network size of 363.5 without considering gender. In their work, 10 known population subgroups were used and, after removing 7 groups, 3 groups (male firefighters, the police, and army) were used to calculate the social network size. In a study in Japan, only 3 known subgroups were used for social network size estimation, while different studies demonstrated that at least 2030 known subgroups must be employed to increase the accuracy of estimations. In the study in Kerman, only 6 names were used as known populations, whereas more subgroups should have been included. Therefore, these drawbacks might have caused an overestimation of the $\mathrm{C}$-value in these studies $(1,5,18,21,22)$.

In the study by Killworth et al, the estimated social network size was 286 , which was smaller than the value reported in the present study. Moreover, in a study conducted by McCarty et al in the United States, the average number obtained for the social network size was 291. In a study in Ukraine, the social network size was estimated 202 using the NSU method, while the calculation method was the NSU approach and estimation method was MLE, similar to the present study. Other factors contributing to the difference between social network sizes in these studies can be cultural differences, different regions, variations in population composition of participants, and size of regions where the studies were conducted $(1,7,18)$.

In the univariate analysis, the social network size of the residents of Iranshahr was affected by gender, marital status, education level, occupation, and place of residence. In a study conducted in Kerman Province, the social network size of young men was affected by age and level of education. However, in the multivariate analysis, there was no significant relationship between social network size in Kerman and any of the demographic factors in this study (age, gender, marital status, and occupation) (5). Consistent with the Iranian national study and the study conducted in China, the results of the present study revealed that men, compared to women, and younger people, compared to older ones, had a significantly larger social network. This has been attributed to social and cultural considerations. In contrast to the national study and studies in Kerman and Tehran where the younger age group (18-25 years) had a larger social network size, the social network size was larger in 25-39 age group in the present study, compared to other age groups, but had no significant relationship with the average social network size. This might have been due to the active participation of this age group in the present study. In a study conducted in China, the social network size of married people was larger than that of the single, which was in contrast to the present research. Moreover, in the study by Shati et al, the social network size of married people was larger than that of the single, but the difference was not statistically significant (248.8 vs 270.1), while it was significant in the present study (331.5 vs 301.6). In the national study and the study in Kerman, the social network size of single people was larger than that of the married. In the present study, the social network size was larger in those with a higher education level, consistent with the results of the national study. Moreover, in this study, employees had a larger social network than those with other occupations, while university students had a wider social network in the studies in Kerman and Tehran $(1,5,11,23)$.

This study had some limitations. The first limitation, which can also be found in other studies, is related to the definitions of the studied subpopulations in the minds of the participants (1). Despite the precise definition of "knowing", the information required for this type of studies is collected based on the self-declaration of individuals, resulting in the insufficient accuracy of estimation. Therefore, in this study, subpopulations that could be identified and remembered by participants in a short time were used. Lack of familiarity of some participants with Persian language was another limitation of the present study. Therefore, to overcome this problem, native interviewers familiar with the local language were recruited.

\section{Conclusion}

The social network size calculated in this study with the ratio-based approach was smaller than the value reported in the national study. It appears that the difference in the methodology of social network size calculation and use of different known subpopulations are the reasons for differences in the estimation of the social network size in various studies. 
Moreover, conducting a study in urban and rural areas may lead to differences in the estimated social network size. Other reasons could be cultural and social differences in various regions and countries. The difference in the demographic characteristics of participants can also affect the social network size of people.

\section{Ethical considerations}

Ethical considerations (obtaining informed consent and avoiding plagiarism, falsification were considered in the present study.

\section{Acknowledgments}

The present study was supported by Iran University of Medical Sciences, Tehran, Iran, with the collaboration of Iranshahr University of Medical Sciences and Health Services, Sistan and Baluchestan Province.

\section{Conflict of Interests}

The authors declare that they have no competing interests.

\section{References}

1. Shati M, Haghdoost A, Majdzadeh R, Mohammad K, Mortazavi S. Social Network Size Estimation and Determinants in Tehran Province Residents. Iran J Public Health. 2014:1079-90.

2. Wang J, Yang Y, Zhao W, Su H, Zhao Y, Chen Y, et al. Application of network scale Up method in the estimation of population size for men who have sex with men in Shanghai, China. 2015.

3. Haghdoost AA, Baneshi MR, Haji-Maghsoodi S, Molavi-Vardanjani $\mathrm{H}$, Mohebbi E. Application of a network scale-up method to estimate the size of population of breast, ovarian/cervical, prostate and bladder cancers. Asian Pac J Cancer Prev. 2015;16:3273-7.

4. Bernard HR, Hallett T, Iovita A, Johnsen EC, Lyerla R, McCarty C, et al. Counting hard-to-count populations: the network scale-up method for public health. Sex Transm Infect. 2010:81-8.

5. Shokoohi M, Baneshi M, Haghdoost A. Estimation of the active network size of Kermanian Males [Internet]. Addict Health. 2010;2:818.

6. Salganik MJ, Fazito D, Bertoni N, Abdo AH, Mello MB, Bastos FI. Assessing network scale-up estimates for groups most at risk of HIV/AIDS: Evidence from a multiple-method study of heavy drug users in Curitiba, Brazil. Am J Epidemiol. 2011;174(10):1190-6.

7. McCarty C, Killworth PD, Bernard HR, Johnsen EC, Shelley GA. Comparing two methods for estimating network size. Hum Organ [Internet]. 2001;60(1):28-39.

8. McCormick TH, Salganik MJ, Zheng T. How Many People Do You Know?: Efficiently Estimating Personal Network Size. J Am Stat Assoc [Internet]. 2010;105(489):59-70.

9. Salganik MJ, Fazito D, Bertoni N, Abdo AH, Mello MB, Bastos FI. Assessing network scale-up estimates for groups most at risk of HIV/AIDS: Evidence from a multiple-method study of heavy drug users in Curitiba, Brazil. Am J Epidemiol. 2011;174(10):1190-6.

10. Rastegari A, Haji-Maghsoudi S, Haghdoost A, Shatti M, Tarjoman T, Baneshi MR. The estimation of active social network size of the Iranian population. Glob J Health Sci. 2013;5:217-27.

11. Ezoe S, Morooka T, Noda T, Sabin ML, Koike S. Population size estimation of men who have sex with men through the network scaleup method in Japan. PLoS One. 2012:7(1).

12. Paniotto V, Petrenko T, Kupriyanov OPO. Estimating the size of populations with High Risk for HIV Using Network Scale-Up Method. Ukr Int Inst Sociol. 2009.

13. Sulaberidze L, Mirzazadeh A, Chikovani I, Shengelia N, Tsereteli N, Gotsadze G. Population Size Estimation of Men Who Have Sex with Men in Tbilisi, Georgia; Multiple Methods and Triangulation of Findings. PLoS One. 2016;11(2).

14. Wang J, Yang Y, Zhao W, Su H, Zhao Y, Chen Y, et al. Application of Network Scale Up Method in the Estimation of Population Size for Men Who Have Sex with Men in Shanghai, China. PLoS One. 2015;10(11)

15. Feehan DM, Umubyeyi A, Mahy M, Hladik W, Salganik MJ. Quantity Versus Quality: A Survey Experiment to Improve the Network Scale-up Method. Am J Epidemiol. 2016;183(8):747-57.

16. World Bank Group. Estimating the Size of Populations through a Household Survey (ESPHS) [Internet]. 2011:1-114

17. Habecker P, Dombrowski K, Khan B. Improving the Network Scale-Up Estimator: Incorporating Means of Sums, Recursive Back Estimation, and Sampling Weights. PloS One. 2015:1-16

18. Jafari Khounigha A, Haghdoostb AA, Salari Lakc Sh, Hossein Zeinalzadehd A, Yousefi Farkhade R, Mohammadzadehe M, et al. Size Estimation of Most-at-Risk Groups of HIV/AIDS Using Network Scale-up in Tabriz, Iran. J Clin Res Gover. 2014;3(1):21-6.

19. Report T. Consultation on Network scale-up and other size estimation methods from general population surveys. UNAIDS Refrence Group on Estimate, Modelling and Projections . 2012.

20. Zamanian M, Baneshi MR, Haghdoost AA, Mokhtari-Sorkhani T, Amiri F, Zolala F. Estimating the Size and Age-gender Distribution of Women's Active Social Networks. Addict Health. 2016;8(3):170178.

21. Ezoe S, Morooka T, Noda T, Sabin ML, Koike S. Population size estimation of men who have sex with men through the network scaleup method in Japan. PloS One. 2012.

22. Epidemic monitoring and Analysis U. Network scale-up: a promising method for national estimates of the sizes of populations at higher risk. 2010:1-7.

23. Bao SL, Wu GH, Zhang W, Zhou C, Guo W, Zhou XL, et al. [Application on size estimation through the network scale-up method on men who have sex with men in Chongqing municipality]. Zhonghua Liu Xing Bing Xue Za Zhi. 2012 Oct;33(10):1036-9. [Article in Chinese] 
Appendix Table 1. The Sub-groups of known population used to estimate the social network, ratio of real number to population province

\begin{tabular}{|c|c|c|}
\hline Reference group & Ratio of real number to population province & Consideration \\
\hline Started elementary school last year & 3.85 & Staying in the final analysis \\
\hline Studied at elementary school last year & 13.61 & Omitted in the beginning of analysis \\
\hline Graduated from high school last year & 5.82 & Omitted in the beginning of analysis \\
\hline Took part in university entrance exam last year & 1.40 & Staying in the final analysis \\
\hline Started studying at a state university last year & 0.41 & Staying in the final analysis \\
\hline Has done military services during the last year & - & Omitted in the beginning of analysis \\
\hline Last year, was admitted to environmental health & 0.001 & Omitted in the beginning of analysis \\
\hline Officially married last year & 0.79 & Staying in the final analysis \\
\hline Officially divorced last year & 0.065 & Omitted in the beginning of analysis \\
\hline Had a normal delivery last year & $1 / 007$ & Staying in the final analysis \\
\hline Had a cesarean section last year & 0.17 & Staying in the final analysis \\
\hline Had been abroad during the last year & - & Omitted in the beginning of analysis \\
\hline Had been in Hadj(Mecca) during the last year & 0.03 & Omitted in the beginning of analysis \\
\hline Had an office job in an elementary school & 0.82 & Staying in the final analysis \\
\hline Had talassemia & 0.12 & Excluded from final calculation \\
\hline Absolute blinding & 0.002 & Omitted in the beginning of analysis \\
\hline One leg handicapped & 0.001 & Omitted in the beginning of analysis \\
\hline One hand handicapped & 0.0007 & Omitted in the beginning of analysis \\
\hline Died due to car accident in the last year & 0.06 & Omitted in the beginning of analysis \\
\hline Suffers from retardation & 0.14 & Excluded from final calculation \\
\hline Her name is Asieh & 0.76 & Staying in the final analysis \\
\hline His name is Abdullah & 0.60 & Staying in the final analysis \\
\hline Her name is Sonya & 0.06 & Omitted in the beginning of analysis \\
\hline Her name is Samira & 0.38 & Staying in the final analysis \\
\hline His name is Yasser & 0.38 & Staying in the final analysis \\
\hline His name is Yasin & 0.09 & Omitted in the beginning of analysis \\
\hline Her name is Yasna & 0.29 & Staying in the final analysis \\
\hline Her name is Tahora & 0.03 & Omitted in the beginning of analysis \\
\hline Her name is Matin & 0.16 & Excluded from final calculation \\
\hline Her name is Omar & 0.30 & Excluded from final calculation \\
\hline
\end{tabular}

